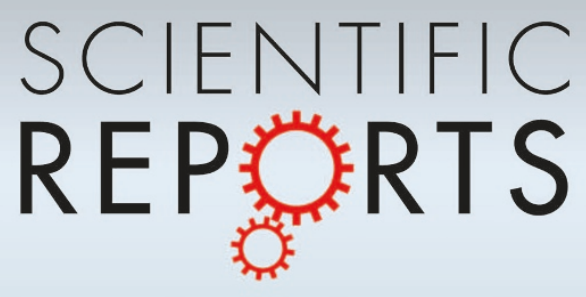

OPEN

SUBJECT AREAS:

ENVIRONMENTAL

SCIENCES

ENVIRONMENTAL MONITORING

ATMOSPHERIC CHEMISTRY

GEOCHEMISTRY

Received

12 June 2013

Accepted

15 August 2013

Published

30 August 2013

Correspondence and requests for materials should be addressed to

K.A. (adachik@mrijma.go.jp)

\section{Emission of spherical cesium-bearing particles from an early stage of the Fukushima nuclear accident}

\author{
Kouji Adachi, Mizuo Kajino, Yuji Zaizen \& Yasuhito Igarashi
}

Meteorological Research Institute, 1-1 Nagamine, Tsukuba, Ibaraki, Japan 305-0052.

The Fukushima nuclear accident released radioactive materials into the environment over the entire Northern Hemisphere in March 2011, and the Japanese government is spending large amounts of money to clean up the contaminated residential areas and agricultural fields. However, we still do not know the exact physical and chemical properties of the radioactive materials. This study directly observed spherical Cs-bearing particles emitted during a relatively early stage (March 14-15) of the accident. In contrast to the Cs-bearing radioactive materials that are currently assumed, these particles are larger, contain $\mathrm{Fe}, \mathrm{Zn}$, and $\mathrm{Cs}$, and are water insoluble. Our simulation indicates that the spherical Cs-bearing particles mainly fell onto the ground by dry deposition. The finding of the spherical Cs particles will be a key to understand the processes of the accident and to accurately evaluate the health impacts and the residence time in the environment.

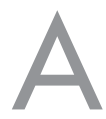

$\mathrm{n}$ earthquake with a magnitude of 9.0 occurred in Japan on March 11, 2011. In addition to the earthquake itself, a tsunami struck along the east coast of Honshu and damaged the Fukushima Daiichi nuclear power plant (FNPP). The FNPP eventually lost its ability to cool the nuclear fuel, which caused hydrogen explosions and released radioactive materials into the environment ${ }^{1,2}$. Because of the local contamination, many people still cannot return home. Currently, the Japanese government is spending considerable amounts of money to clean up the contaminated residential environment and agricultural fields.

The radioactive materials released to the atmosphere traveled over the entire Northern Hemisphere ${ }^{3-7}$. In Europe, for example, Masson et al. ${ }^{3}$ measured increases in radioactive cesium and iodine in the air from March 19, 2011 and showed that the maximum levels occurred between March 28 and 30. Although the accident has global impacts, we still do not know exactly what happened in the reactors during the accident, and the estimates of the radioactive Cs releases vary largely from 9 to $36 \mathrm{PBq}^{6,8-10}$.

The chemical and physical properties (i.e., chemical forms, particle sizes, shape, phases (gas or aerosol), water solubility, and residence time) of the radioactive materials released into the environment are not well known ${ }^{11}$. Such knowledge is necessary to improve the numerical models to estimate the geographical distributions and evaluate the human exposures during and after the accident. Because the mass of released radioactive material was small, i.e., the release of ${ }^{137} \mathrm{Cs}$ from the accident was $<20 \mathrm{~kg}$, and the material spread globally, it is extremely difficult to chemically detect it other than by radioactivity detectors. In this study, we chemically detected Cs within single particles for the first time by using electron microscopy and report the shape, composition, water solubility, and sizes of the particles to evaluate the implications of their formation process, occurrences in the environment, and potential health effects. This knowledge is still important for preventing further accidents, finding effective ways to remove the radioactive materials from the environment, and preventing further resuspention of the materials.

\section{Results}

Two plume events. The major radioactive material release events occurred during March 12 and 23, 2011 at the FNPP $^{5}$. We collected aerosol samples on quartz fiber filters $(25 \mathrm{~cm} \times 20 \mathrm{~cm})$ at the Meteorological Research Institute, Tsukuba, Japan, which is located $170 \mathrm{~km}$ southwest of FNPP (see the Method section). In these samples, we found two significant peaks in the radioactivity concentrations between March 14 and 15 (Plume 1) and between March 20 and 22 (Plume 2) (Fig. 1). These significant plumes in the air were also reported in eastern Japan and polluted the water and soil ${ }^{2,12-15}$. Meteorological conditions, such as rain and the wind direction, and the releases of radioactive materials were the main causes of the high surface deposition events ${ }^{14}$. We used the 


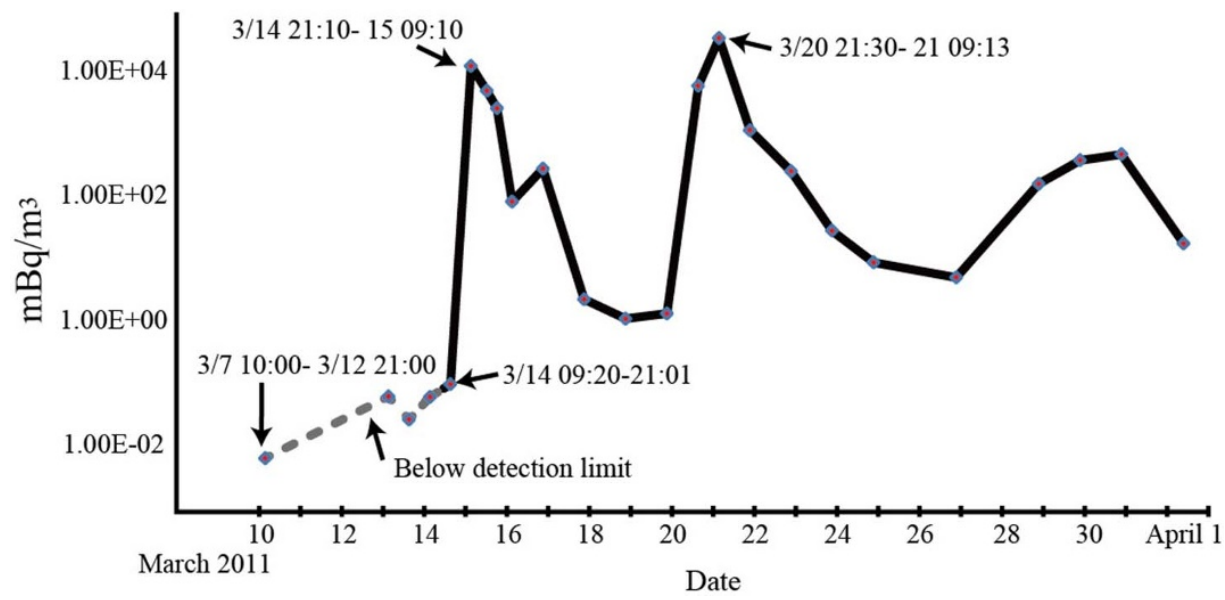

Figure $1 \mid$ The radioactivity of the aerosol particles after the Fukushima Daiichi nuclear power plant accident in Tsukuba, Japan. Red dots indicate the midpoints of each sampling period.

filters that had the maximum radioactivity levels from each plume (from March 14, 21:10 (local time) to March 15, 09:10 and from March 20, 21:30 to March 21, 09:13) and analyzed portions of these filters $\left(\sim 10 \mathrm{~cm}^{2}\right.$ per filter) using an imaging plate (IP) and a scanning electron microscope (SEM) to directly observe the radioactive materials. In addition, we measured the aerosol particle size distributions within the plumes (Figs. S1 and S2).

First plume (March 14-15). We measured the radioactive materials that were collected in the filter at ground level on March 14-15 using the IP (Fig. 2). The radioactive materials were distributed spotty, suggesting that the number of radioactive particles was relatively small but that their activity levels were relatively strong. Within this filter sample, we counted approximately 100 spots caused by radioactive materials, suggesting a concentration of approximately 10 radioactive particles per $\mathrm{m}^{3}$. For reference, the average particle number concentration was $4.1 \times 10^{7}$ per $\mathrm{m}^{3}$ for particles larger than $0.5 \mu \mathrm{m}$ from March 15 (Fig. S1). The spotty distribution in the IP image was also observed in the rooftop filter sample from March 15 (Fig. S3).

To detect radioactive particles using SEM, it is necessary to reduce the number of non-radioactive particles on the filter. Therefore, we cut the filter into many small parts to include the radioactive spots features (Fig. S4). We then measured the radioactivity of each segment using IP and/or a Ge detector to chase the radioactive particle. After reducing the particle numbers in the segments from the three radioactive spots, we used the SEM and found three radioactive Csbearing particles.

In Figure 3, we show a particle containing Cs (Cs Particle 1). The particle is spherical with a diameter of $2.6 \mu \mathrm{m}$. The energy dispersive X-ray spectrometer (EDS) spectrum shows Cs peaks. The Cs distribution in the elemental mapping image indicates that the spherical particles consist of Cs along with substantial amounts of $\mathrm{Fe}$ and $\mathrm{Zn}$ and minor amounts of $\mathrm{Cl}, \mathrm{Mn}$, and $\mathrm{O}$. The decay-corrected activity (as of March 2011) of Cs Particle 1 is $3.27 \pm 0.04$ and $3.31 \pm 0.06 \mathrm{~Bq}$ for ${ }^{137} \mathrm{Cs}$ and ${ }^{134} \mathrm{Cs}$, respectively
3/14 21:10-3/15 09:10

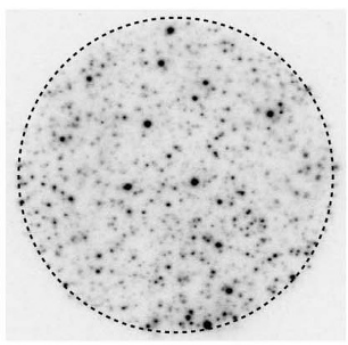

3/15 21:11-3/16 09:00

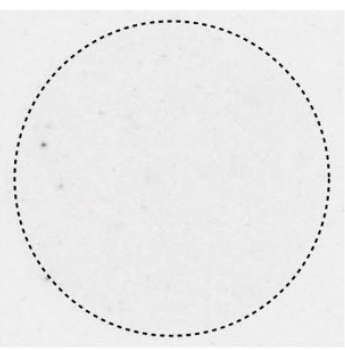

3/15 09:19- 3/15 15:22

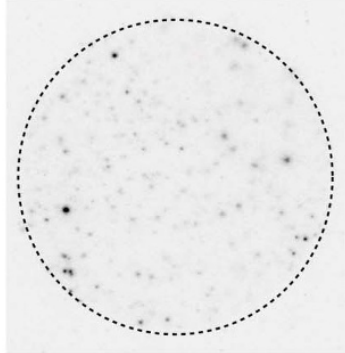

$3 / 2021: 30-3 / 2109: 13$

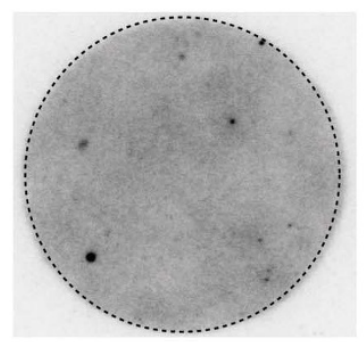

3/15 15:30-3/15 21:02

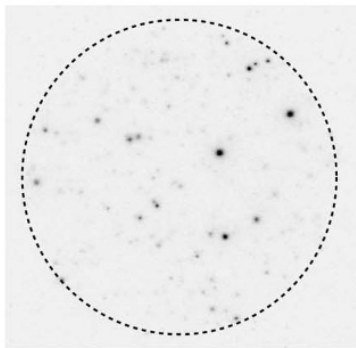

$3 / 2109: 18-3 / 2121: 20$

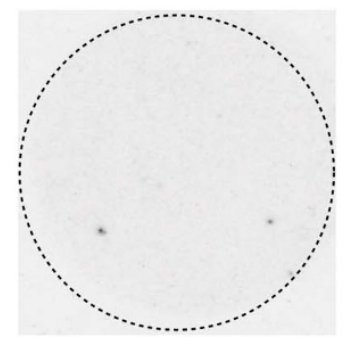

Figure $2 \mid$ The distribution of radioactive materials on the filter samples measured with the IP. Black dots indicate the presence of radioactive materials. The outer rims (dotted line) of the filters were added artificially. This study focused on the filter samples from March 14, 21:10 to March 15, 09:10 (upper left), and from March 20, 21:30 to March 21, 09:13 (bottom center). 
a)

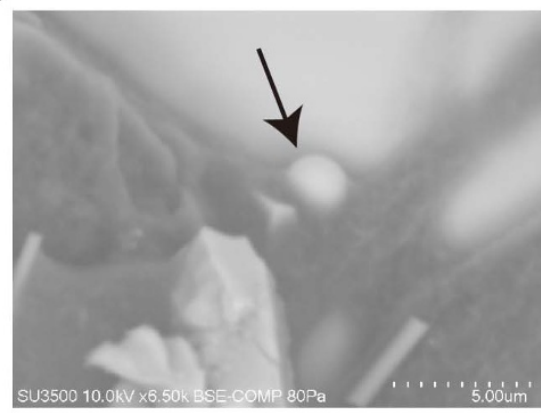

c)

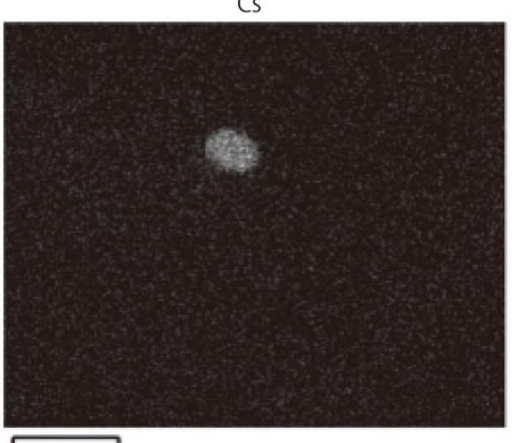

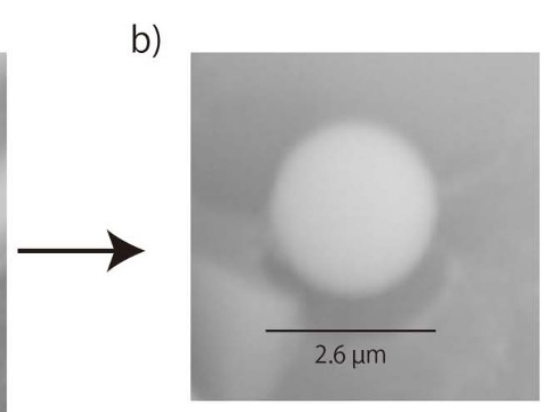

d)

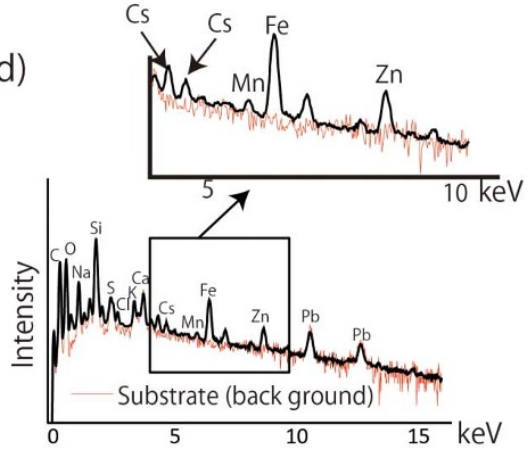

$\mathrm{Si}$

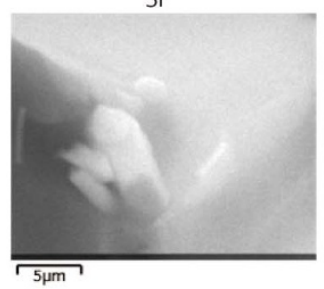

$\mathrm{Fe}$

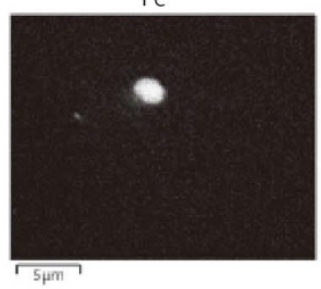

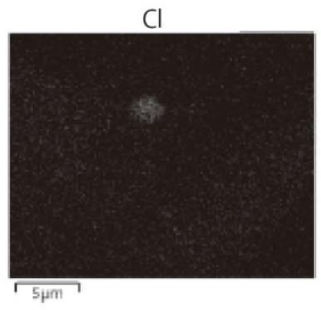

$\mathrm{Zn}$

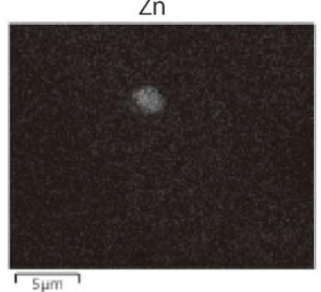

Figure 3 SEM and EDS mapping images of a radioactive Cs-bearing particle from the sample collected during March 14, 21:10 and March 15, 09:10. (a) A Cs-bearing particle partially embedded within a carbon paste. (b) The same Cs-bearing particle as a) but measured the next day. The particle shows a spherical shape. (c) An elemental mapping (Cs) of the particle (a). (d) The EDS spectrum of the particle a) (black line). The red line shows the spectrum from the glass substrate. The $\mathrm{Cs}$ in the particle shows multiple peaks. (e) An elemental mapping of the other elements within the area. $\mathrm{O}$, Si, $\mathrm{Cl}$, $\mathrm{Mn}, \mathrm{Fe}$, and $\mathrm{Zn}$ are possibly coexistent with $\mathrm{Cs}$ within the particle.

(Fig. S5). Assuming a particle density of $2.0 \mathrm{~g} / \mathrm{cm}^{3}$, the Cs mass percentage within the particle is estimated from its activity $(\mathrm{Bq})$ to be 5.5. Another Cs-bearing particles (Cs particles 2 and 3) from the same filter but different spots are similar to Cs Particle 1, although they have weaker activity (Fig. S6). The particles consist of $\mathrm{Fe}, \mathrm{Zn}$, and $\mathrm{Cs}$ and are approximately $2.0 \mu \mathrm{m}$ in diameter. The radioactivity for Cs particle 2 is $0.66 \pm 0.02$ and $0.78 \pm 0.04 \mathrm{~Bq}$ for ${ }^{137} \mathrm{Cs}$ and ${ }^{134} \mathrm{Cs}$, respectively. The Cs mass percentage within Particle 2 is estimated from its activity to be 2.5. Assuming that the entire the radioactivity in the Plume 1 was from the Cs-bearing spherical particles gives an average of $1.4 \mathrm{~Bq}$ per particle, which is comparable to that of Particle 2 .

We analyzed the water solubility of Cs Particle 1 by comparing the particle's shape before and after exposure to water (Fig. S7). The results show that there was no change in shape, suggesting that the particle was insoluble to water at least during atmospheric transportation.

Second plume (March 20-21). The IP image of the filter collected on March 20-21 indicates that the radioactive materials are evenly distributed within the filter with approximately 10 diffused spots (Fig. 2). We cut the filter including a diffused spot, formed several layers, and captured the IP image (Fig. S8). The radioactivity is distributed along the filter segments, a result which differs from that of Plume 1 . We interpret that small amounts of the radioactive Cs attach to other dominant aerosol particles and that the occurrence is consistent with the results of Kaneyasu et al. ${ }^{16}$ about the role of sulfate aerosols as carriers of ${ }^{137} \mathrm{Cs}$. An SEM analysis with EDS elemental mapping shows numerous sulfate and mineral dust, as is commonly found in aerosol samples (Fig. S8). The aerosol filter 
Plume 1 (March 14-15, 2011)

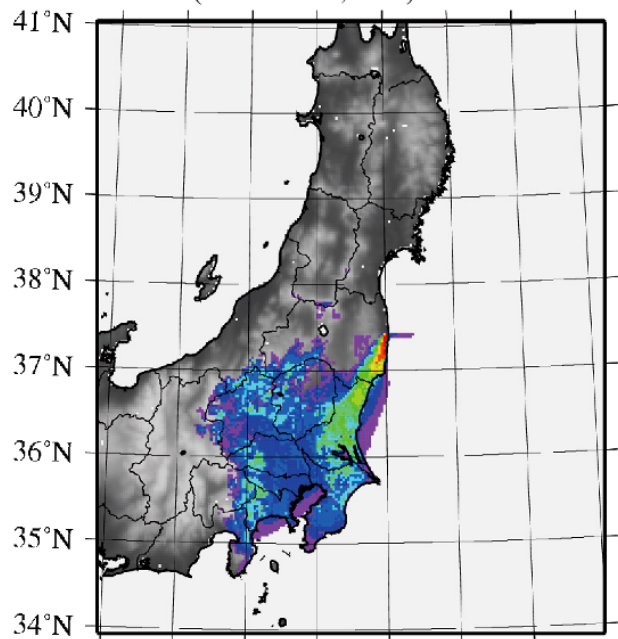

$137^{\circ} \mathrm{E} 138^{\circ} \mathrm{E} 139^{\circ} \mathrm{E} 140^{\circ} \mathrm{E} 141^{\circ} \mathrm{E} 142^{\circ} \mathrm{E} 143^{\circ} \mathrm{E}$
$\left[\mathrm{kBq} / \mathrm{m}^{2}\right]$

100.0

50.0

10.0

Figure $4 \mid$ The model simulation of the total deposition of the ${ }^{137} \mathrm{Cs}$ released from the FNPP in Plume 1 (between March 14, 17:00 and March 15, 02:00 (JST)). We assumed that all Cs consists of relatively large, waterinsoluble particles. The Regional Air Quality Model 2 (RAQM2 ${ }^{17}$ ) was used for the model calculation. We used the Generic Mapping Tools (GMT) developed at University of Hawaii to draw the figure. The model elevation in the figures was generated based on a $1 \mathrm{~km}$ resolution Global $30 \mathrm{Arc}-$ Second Elevation (GTOPO30) of U.S. Geological Survey (USGS).

sample from the rooftop site also indicates a similar distribution of radioactive materials (Fig. S3).

Model. We simulated the depositions of the radioactive particles from Plumes 1 and 2 using a tagged chemical transport model. Unlike other simulation models (e.g., ${ }^{4,6,9,12}$ ), we considered the aerosol dynamical processes explicitly and used the measured values and assumptions of the particle physical and chemical properties from our observations, i.e., on March 14-15, radioactive Cs consisted of $2.3 \mu \mathrm{m}$ hydrophobic particles, whereas on March 20-21, the Cs was carried by hydrophilic submicron particles (e.g., sulfate).

The tagged simulation result indicates that the aerosol particles on the filter sample from Plume 1 were mainly emitted during March 14, 17:00 to March 15, 02:00 (JST) from the FNPP. On the other hand, the aerosol particles on the filter sample from Plume 2 were mainly emitted during March 19, 20:00 and March 20, 07:00.

In Figure 4, we show simulation of the total (dry + wet) ${ }^{137} \mathrm{Cs}$ deposition. Within Plume $1,17 \%$ and $5.1 \times 10^{-3} \%$ of the ${ }^{137} \mathrm{Cs}$ released from the FNPP fell onto the ground by dry and wet deposition processes, respectively, and the rest $(83 \%)$ was deposited into the ocean or was transported out of the model domain. In contrast, the deposition ratios onto the ground for the particles within Plume 2 were $1.9 \%$ and $3.8 \%$ by dry and wet deposition, respectively.

\section{Discussion}

This study reports for the first time the presence of spherical radioactive Cs-bearing particles emitted from the FNPP during a relatively early stage (March 14-15) of the accident. The particles coexist with $\mathrm{Fe}, \mathrm{Zn}$, and possibly other elements, and their diameters are approximately $2 \mu \mathrm{m}$. Because these elements were evenly distributed within the particle, we conclude that they are internally mixed and form an alloy. This result differs from that reported by Kaneyasu et al. ${ }^{16}$, who showed that the Cs measured on samples collected during April and May 2011 was carried by sulfate aerosol particles approximately $0.5 \mu \mathrm{m}$ in size. Due to its spherical shape and composition, the particle is likely solid and is largely insoluble in water. Spherical aerosol particles, such as fly ash, commonly form from liquidized materials or during the condensation of vaporized materials depending on their sizes ${ }^{17}$.

The spherical Cs-bearing particles were larger and less water soluble than sulfate particles, resulting in more dry deposition and less deposition in the region northwest of the FNPP (Figs. 4 and S9). If we assume that all of the Cs had been carried by the sulfate aerosol particles in Plume 1, 5.6\% and 9.3\% of the released ${ }^{137} \mathrm{Cs}$ should have been deposited through dry and wet deposition processes, respectively. Accordingly, the geographical distribution of Cs deposition differs depending on the physical and chemical properties (Fig. S9), although the quantitative radioactivity levels for the total deposition in the model depend on assumptions such as cloud microphysics and the total amount of emissions from the FNPP, which is still under debate. Our model results suggest that because the dry and wet deposition processes are sensitive to the chemical form and sizes of the Cs carriers, multiple numerical simulation models based on the accurate chemical and physical properties of Cs-bearing particles will be needed to reevaluate how the Cs from the early stages of the accident was deposited.

It is probable that the emission processes had changed between the emissions of Plumes 1 and 2 as the accident and water injection progressed; however, further studies will be needed to reveal the emission process during the accident.

This study aims to show the presence of spherical radioactive Csbearing particles to stimulate and facilitate further studies across multidisciplinary fields that will enable the proper understanding and evaluation of particle effects. We believe the finding of the Csbearing particles will have implications to the following studies.

1) The composition and the spherical shape of the Cs-bearing particles emitted by the FNPP accident will be a key to understand what happened in the nuclear reactors during the accident.

2) The spherical Cs-bearing particles likely have longer retention times on the land surface than those of the water-soluble Cs particles. The retention time of the particles in the soil or other environments needs to be reconsidered.

3) The health effects of the particles should be evaluated based on the particle sizes and insolubility in water.

\section{Methods}

Sampling. The samples were collected at the Meteorological Research Institute (Tsukuba, 36.05N, 140.13E) using both a high-volume aerosol sampler (Sibata Scientific Technology ltd., HV-1000F; $1000 \mathrm{~m}^{3} / 24 \mathrm{~h}$ ) placed on the ground and a PM2.5 aerosol sampler $\left(24 \mathrm{~m}^{3} / 24 \mathrm{~h}\right)$ placed on the roof of the 6-floor building (approximately $25 \mathrm{~m}$ from ground level). Quartz fiber filters were used in both samplers. The sampling times were 6,12 , or $24 \mathrm{~h}$ for the high volume air sampler and $24 \mathrm{~h}$ for the PM2.5 aerosol sampler. The particle size distributions were monitored using an aerosol particle sizer (APS; TSI-3321) and a scanning mobility particle sizer (SMPS; TSI-3080 and TSI-3775) on the rooftop site for particle sizes $>0.5 \mu \mathrm{m}$ and between 7 and $289 \mathrm{~nm}$ in diameter, respectively, with a $2.5 \mu \mathrm{m}$ cutoff size.

Analyses. An imaging plate (IP; GE CRx25P) was used to detect the radioactivity on the filters with a pixel spatial resolution of $50 \mu \mathrm{m}$. An intrinsic Ge detector (SEIKO EG\&G) coupled with a multi-channel analyzer was used to obtain the gamma spectra of each Cs-bearing particle and filters. A scanning electron microscope (SEM; Hitachi high-Technologies SU 3500) and an energy dispersive X-ray spectrometer (EDS; Horiba ltd. X-max $50 \mathrm{~mm}$ ) were used to observe and analyze the shapes and compositions of the particles. The particles attached to the filter fibers were mounted within a carbon tape (Fig. S4). A manipulator (Micro Support Corp., AP-xy-01) was used to cut the carbon tape into as small segments as possible $(<0.1 \mathrm{~mm})$.

Model. We used the Regional Air Quality Model $2\left(\mathrm{RAQM} 2^{18}\right)$, which implements a triple-moment modal aerosol dynamics module assuming a log-normal size distribution of the aerosol populations. This model describes the nature of the aerosol dynamical processes, such as nucleation, condensation, coagulation, dry deposition, grid-scale cloud condensation and ice nuclei activation, and the subsequent cloud microphysical processes (rainout) and the washout processes. A non-hydrostatic meteorological model (NHM) ${ }^{19}$ was used to produce the meteorological field. There were $215 \times 259$ grids with a $3 \mathrm{~km}$ horizontal grid resolution in both the NHM and RAQM2. There were 50 vertical layers to $50 \mathrm{hPa}$ in the NHM, and 20 layers to $10 \mathrm{~km}$ in the RAQM2. The Japan Meteorological Agency (JMA) Meso-Regional Objective 
Analysis data sets $(3 \mathrm{~h}, 5 \mathrm{~km} \times 5 \mathrm{~km})$ were used for the initial and boundary conditions for the NHM and for the spectral nudging method. The ${ }^{137} \mathrm{Cs}$ released from the FNPP was tagged with a temporal resolution of 1 hour. We assumed $0.43 \mathrm{PBq}$ (Plume 1) and $0.39 \mathrm{PBq}$ (Plume 2) for the total amounts of ${ }^{137} \mathrm{Cs}$ activity released from the FNPP by using the inventory of Katata et al. ${ }^{20}$. We used a number equivalent geometric mean dry diameter $D_{g, n, d r y}=2.3 \mu \mathrm{m}$ (an averaged value of the Cs-bearing particles 1 and 2), geometric standard deviation $\sigma_{\mathrm{g}}=1.3$, particle density $\rho_{p}=2.0 \mathrm{~g} /$ $\mathrm{cm}^{3}$, and hygroscopicity $\kappa=0$ for Plume 1 . For Plume 2, we used $D_{g, n, d r y}=102 \mathrm{~nm}$ (measured by SMPS), $\sigma_{\mathrm{g}}=1.6, \rho_{p}=1.83 \mathrm{~g} / \mathrm{cm}^{3}$, and $\kappa=0.4$. The calculated dry deposition velocities of the particles in Plume 1 are approximately 4-5 times greater than those of the particles in Plume 2. For the particles in Plume 2, both the rainout and washout processes were considered, whereas for particles in Plume 1, only washout was considered because no cloud condensation nuclei activity is assumed (i.e., $\kappa=0$ ).

1. Yoshida, N. \& Kanda, J. Tracking the Fukushima radionuclides. Science 336 1115-1116 (2012)

2. MEXT: Japanese Ministry of Education, Culture, Sports, Science and Technology, http://www.mext.go.jp/english, accessed on May, 07, 2013.

3. Masson, O. et al. Tracking of airborne radionuclides from the damaged Fukushima Dai-ichi nuclear reactors by European networks. Environ Sci. Technol. 45, 7670-7677 (2011).

4. Takemura, T. et al. A numerical simulation of global transport of atmospheric particles emitted from the Fukushima Daiichi Nuclear Power Plant. Sola 7, 101-104 (2011).

5. Achim, P. et al. Analysis of radionuclide releases from Fukushima Dai-Ichi Nuclear Power Plant accident Part II. Pure Appl. Geophys. 10.1007/s00024-0120578-1 (2012).

6. Stohl, A. et al. Xenon-133 and caesium-137 releases into the atmosphere from the Fukushima Dai-ichi nuclear power plant: determination of the source term, atmospheric dispersion, and deposition. Atmos. Chem. Phys. 12, 2313-2343 (2012)

7. Christoudias, T. \& Lelieveld, J. Modelling the global atmospheric transport and deposition of radionuclides from the Fukushima Dai-ichi nuclear accident. Atmos. Chem. Phys. 13, 1425-1438 (2013).

8. Chino, M. et al. Preliminary estimation of release amounts of ${ }^{131} \mathrm{I}$ and ${ }^{137} \mathrm{Cs}$ accidentally discharged from the Fukushima Daiichi nuclear power plant into the atmosphere. J. Nucl. Sci. Technol. 48, 1129-1134 (2011).

9. Katata, G., Ota, M., Terada, H., Chino, M. \& Nagai, H. Atmospheric discharge and dispersion of radionuclides during the Fukushima Dai-ichi Nuclear Power Plant accident. Part I: Source term estimation and local-scale atmospheric dispersion in early phase of the accident. J. Environ Radioactivity 109, 103-113 (2011).

10. Winiarek, V., Bocquet, M., Saunier, O. \& Mathieu, A. Estimation of errors in the inverse modeling of accidental release of atmospheric pollutant: Application to the reconstruction of the cesium-137 and iodine-131 source terms from the Fukushima Daiichi power plant. J. Geophys. Res. 117, D05122, doi: 10.1029/ 2011JD016932 (2012).

11. Burns, P. C., Ewing, R. C. \& Navrotsky, A. nuclear fuel in a reactor accident. Science 335, 1184-1188 (2012).

12. Morino, Y., Ohara, T. \& Nishizawa, M. Atmospheric behavior, deposition, and budget of radioactive materials from the Fukushima Daiichi nuclear power plant in March 2011. Geophys. Res. Lett. 38, GL048689 (2011).

13. Yasunari, T. J. et al. Cesium-137 deposition and contamination of Japanese soils due to the Fukushima nuclear accident. Proc. Natl. Acad. Sci. USA 108 19447-19448 (2011)
14. Kinoshita, N. et al. Assessment of individual radionuclide distributions from the Fukushima nuclear accident covering central-east Japan. Proc. Natl. Acad. Sci. USA 108, 19526-19529 (2011).

15. Doi, T. et al. Anthropogenic radionuclides in the atmosphere observed at Tsukuba: characteristics of the radionuclides derived from Fukushima. J. Environ Radioactivity 122, 55-62 (2013)

16. Kaneyasu, N., Ohashi, H., Suzuki, F., Okuda, T. \& Ikemori, F. Sulfate aerosol as a potential transport medium of radiocesium from the Fukushima nuclear accident. Environ. Sci. Technol. 46, 5720-5726 (2012).

17. Damle, A. S., Ensor, D. S. \& Ranade, M. B. Coal combustion aerosol formation mechanisms: A review. Aerosol Sci. Technol. 1, 119-133(1981).

18. Kajino, M. et al. Development of the RAQM2 aerosol chemical transport model and prediction of the Northeast Asian aerosol mass, size, chemistry, and mixing type. Atmos. Chem. Phys. 12, 11833-11856 (2012)

19. Saito, K. et al. Nonhydrostatic atmospheric models and operational development at JMA. J. Meteorol. Soc. Jpn. 85B, 271-304 (2007).

20. Katata, G., Ota, M., Terada, H., Chino, M. \& Nagai, H. Atmospheric discharge and dispersion of radionuclides during the Fukushima Dai-ichi Nuclear Power Plant accident. Part I: Source term estimation and local-scale atmospheric dispersion in early phase of the accident. J. Environ Radioactivity 109, 103-113 (2011).

\section{Acknowledgements}

This study was supported by MEXT KAKENHI (a Grant-in-Aid for Scientific Research on Innovative Areas under the A01-01 and A01-02 research teams in the "Interdisciplinary Study on Environmental Transfer of Radionuclides from the Fukushima Daiichi NPP Accident"; grant numbers 24110002 and 24110003, respectively) and the MEXT Japanes Radioactivity Survey. We acknowledge Mr. H. Sako and Mr. T. Kimura (Atox Co. ltd.) for their help with the IP and gamma spectrometry, Ms. C. Takeda (Tokyo Nuclear Services co. ltd.), Ms. K. Inukai, and Ms. K. Kamioka for their help with the HV sampling, and Mr. Y. Iizawa (Tokyo University of Science) for his help with finding the Cs-bearing particle 3 . The PM2.5 filters sampled by Mr. K. Kuchiki and Dr. T. Aoki (MRI) were courteously provided for the present analyses.

\section{Author contributions}

K.A. found the Cs-bearing particles, performed the IP and SEM analyses, and was the primary author of the manuscript; M.K. performed numerical model calculations; Y.Z. performed the SMPS and APS analyses; Y.I. performed the filter sampling and supervised the study; all authors contributed to the manuscript.

\section{Additional information}

Supplementary information accompanies this paper at http://www.nature.com/ scientificreports

Competing financial interests: The authors declare no competing financial interests

How to cite this article: Adachi, K., Kajino, M., Zaizen, Y. \& Igarashi, Y. Emission of spherical cesium-bearing particles from an early stage of the Fukushima nuclear accident. Sci. Rep. 3, 2554; DOI:10.1038/srep02554 (2013).

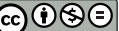

This work is licensed under a Creative Commons Attribution-

NonCommercial-NoDerivs 3.0 Unported license. To view a copy of this license, visit http://creativecommons.org/licenses/by-nc-nd/3.0 